\title{
Information seeking and online learning behaviours - A global study among respiratory physicians
}

\author{
Tania Séverin ${ }^{1}$, Pascal Kurosinksi ${ }^{2}$, Johan Verbraeken ${ }^{3}$, Anita K. Simonds ${ }^{4}$, and Paolo Palange ${ }^{5}$
}

1 Independent CME Professional, Bas-du-Rossé 19, Etoy, Switzerland

2 European Respiratory Society,4 Ave Ste-Luce, Lausanne, Switzerland

3 University Hospital Antwerp, Department of Pulmonary Medicine, Edegem (Antwerp), Belgium

4 Royal Brompton and Harefield NHS Foundation Trust, Clinical and Academic Unit of Sleep \& Breathing, London, United Kingdom

5 University of Rome "La Sapienza", Department of Clinical Medicine, Rome, Italy

Correspondence: Ms Tanya Severin, Etoy, Selfemployed, Bas-du-Rossé 19, CH-1163 Etoy, Switzerland. E-mail: severita@gmx.ch

\section{History}

Received: 2 February 2012

Accepted: 1 May 2012

Published online: 18 May 2012

\section{Abstract}

Objectives: Web-based learning encompasses a wide range of activities. Our purpose is to assess the needs and expectations of respiratory physicians with regard to technology and web offerings in their information seeking and online learning behaviours. Methods: Two surveys were conducted in early 2010 by the European Respiratory Society (ERS) with the aim of understanding the needs and expectations of respiratory physicians with regard to technology and the Internet for learning and teaching purposes. The first survey consisted of 250 telephone interviews. The second survey was conducted online using SurveyMonkey.com platform. Both surveys were analysed separately and results were then collated in an overall analysis. Results: Respondents from all world regions were surveyed. One-third of participants required CME credits for their work and two-thirds were involved in teaching others. Access to journal articles, PowerPoint (PPT) slides and guidelines were considered most important. Further needs and expectations included access to enhanced guideline-related materials, additional videos of medical procedures and quality pictures, $\mathrm{X}$-rays, photos, animations and sounds as well as clinical case studies. Overall, $39 \%$ of the online survey respondents reported using Facebook and $37 \%$ used Medscape as a tool for medical social networking. Finally, fewer than $25 \%$ of respondents reported owning a smartphone and just two-thirds of them used this equipment for professional reasons. Conclusions: Use of educational websites was split between a need to keep knowledge upto-date and assistance in preparing lectures. With regard to the content offered, the most popular features were journal articles and PPT slides, and the most frequently requested features were guideline-related materials: teaching PPT kits and teaching videos. This is a clear indication that even if today's technology allows the creation of many different formats and features, established forms of accessing information and learning are still crucial to both learners and teachers.

Keywords: Internet, $\mathrm{CME}$, information seeking behaviour, technology, online learning, continuing medical education, online CME tests.

\section{Introduction}

In the past decade, Internet use for professional purposes has exploded worldwide. In the past, various studies, conducted primarily in North America, have looked into physicians' use of the Internet for professional and educational purposes, illustrating the growing importance of the worldwide web in health professions. A systematic review of 38 studies conducted between 1994 and 
2004 came to the conclusion that $60-70 \%$ of doctors had access to the Internet, with most of the Internet activity focusing on e-mail and on searching journals and databases. ${ }^{1}$ A few years later, a study commissioned in 2009 by the search giant Google among physicians in the United States showed that $86 \%$ of physicians used the Internet to gather health, medical or prescription drug information, while $78 \%$ performed online CME courses, and 77\% read peer-reviewed journals. ${ }^{2}$ In order to obtain a better understanding of today's use and needs of respiratory physicians in terms of technology and the Internet, an in-depth analysis of respiratory physicians' use of technology as well as perception and needs with regard to the internet in general and to the European Respiratory Society (ERS) education website in particular was conducted. The present article reflects the information obtained from investigating behaviour and learning/teaching needs of a selected population of respiratory physicians.

\section{Methods}

In the field of lung health, the ERS has developed an extensive online resource of multimedia materials over the years. This resource functions both as an online library, which features extensive archive materials from ERS publications and events, and as an interactive e-learning platform containing thematic modules, case reports and quizzes. Materials can be accessed in chronological order by broad themes or through guided learning modules. In order to assess the perception of this educational website among ERS members and to look into the opportunities for further developments, two surveys were conducted.

First, a sample of 250 respondents was interviewed by an external company (MMR Strategy Group, Encino, CA, USA). The level of confidence was 95\% with a margin of error of $\pm 6.12 \%$. Respondents were selected in proportion to the number of members from each region and were representative of each age group. Each interview consisted of a series of closedand open-ended questions. Second, the ERS opened a web survey, using the www.surveymonkey.com survey platform, and invited all its members to participate via email, irrespective of their age group and/or country of residence. Both surveys were first analysed separately and, in the second stage, results were compared and collated.

\section{Results}

A total of 250 respondents participated in the MMR telephone interviews and 296 respondents completed the online survey (76 incomplete responses were filtered out from analysis). While the number of respondents from six out of seven world regions is quite comparable, the number of eastern Europeans who completed the survey was very high: 75 respondents out of 600 members, that is, $12.5 \%$ (Figure 1).

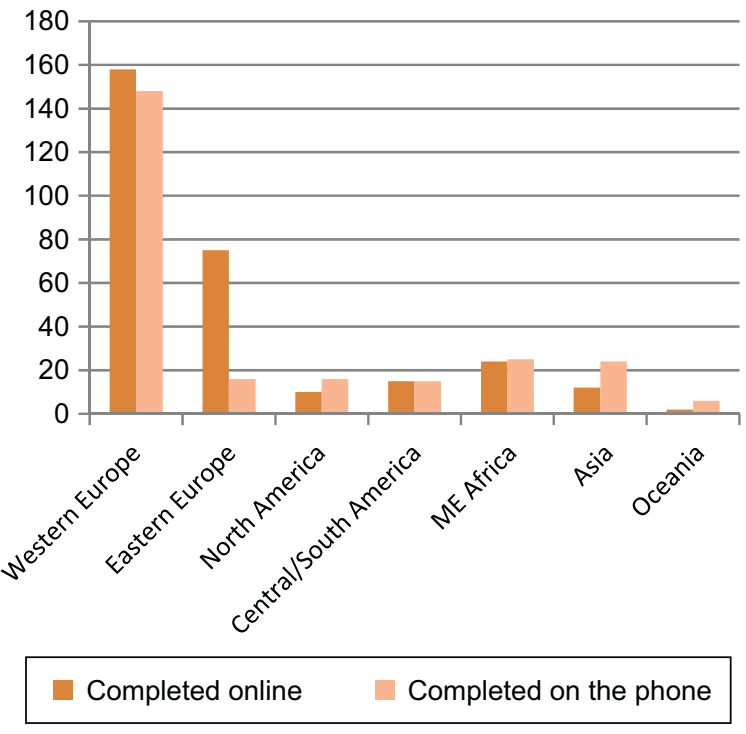

Figure 1. Geographical representation of respondents.

Of the telephone interviewees, $57.2 \%$ were male and $42.8 \%$ were female. For the online survey, $58.1 \%$ of those who completed the survey were male; $41.9 \%$ were female, that is, a very similar representation. Of the respondents to the online survey, $34 \%$ were under 40 years of age, $29 \%$ were aged $41-50$ years, $27 \%$ were aged $41-60$ years and $10 \%$ were above 60 years. For the telephone survey, for which a specific brief to focus on younger members had been given, $52 \%$ of the respondents were under 40 years of age, 20\% were between 41 and 50 years , 21\% were 51-60 years and 7\% were above 60 years. With regard to their main professional role, respondents to both the online and the telephone survey were predominantly respiratory physicians in clinical practice ( $41 \%$ and $48 \%$, respectively), followed by academics ( $15 \%$ and $8 \%)$. Other positions included scientists, allied health professionals, trainees and physicians in private practice. Irrespective of their main position, the great majority of respondents in both surveys reported being involved in teaching, others, with $49 \%$ and $43 \%$ from the online and phone interview groups, respectively, teaching at least weekly (Table 1).

\section{Use of Internet and technology}

Of the survey respondents, $100 \%$ reported using the Internet. Only $23.6 \%$ of the respondents reported use of a smartphone and, among those, $65.5 \%$ reported professional use of their equipment. Of those owning

Table 1. Teaching frequency among respondents.

Teaching frequency Completed online (\%) Completed on the phone (\%)

Daily $\quad 24 \quad 17$

Weekly $25 \quad 26$

Once a month $\quad 28 \quad 13$

A few times a year $\quad 0 \quad 8$

$\begin{array}{lll}\text { Never } & 23 & 36\end{array}$ 
a smartphone, $48.3 \%$ reported using an iPhone, $22.4 \%$ a Blackberry and $10.3 \%$ a Nokia. Of those who used their smartphone for work, 53.4\% reported using it for e-mailing purposes, $36.2 \%$ for accessing the Internet, $7 \%$ for downloading articles and presentations, $5.2 \%$ for downloading podcasts, $3.4 \%$ for doing scientific calculations and 3.4\% for reading articles.

In addition to ERS websites, the websites most frequently accessed by respondents for work purposes were those of the American Thoracic Society (123 respondents), national respiratory/thoracic/chest society (95) and PubMed (93).

Approximately, $96 \%$ of telephone interviewees declared using the Internet for professional networking purposes (Figure 2). Respondents to the online survey were given a list of popular medical social networks and asked to indicate which network they visited. Medscape, which offers a wide range of educational materials (articles, webcasts, podcasts, CME modules) as well as online networking opportunities (forum, chat), ranked highest. Younger respondents were more likely to use medical social networks ( $>35$ years: $45 \%$; $<60$ years: $32.5 \%)$.

In addition, respondents to the web survey were asked which mainstream social networks they used (Figure 3): 115 respondents (39\% of all respondents) indicated that they had a Facebook account, a proportion that decreased with age (54\% of the respondents were in the age group of below 35 years and $12.5 \%$ were above 60 years).

\section{Use of ers-education.org}

This part of the study was aimed at assessing the frequency of the use of the ERS education website as well as looking into the types of materials that are most accessed and needed. Approximately, $81 \%$ of the online survey respondents and $72.8 \%$ of telephone respondents reported regular use of ers-education.org. Regarding the frequency of use, a small number of respondents reported daily use. The majority of respondents reported monthly use on average (Table 2). An analysis by age groups demonstrates significant differences: while 37\% of the respondents aged under 35 reported weekly use of educational resources, and $11 \%$ daily use, only $7 \%$ of the respondents aged over 60 reported weekly use, and $3.5 \%$ daily use.

The main reason reported for not accessing the website was not being aware of the website's existence, which was quoted by $29.4 \%$ (20) of the telephone respondents and $63.2 \%$ (36) of the web survey respondents. Other reasons mentioned were (telephone and web survey): no time (27.9\% and N/A), no need for educational materials (25\% and $8.8 \%$ ), does not match my need (5.9\% and $7 \%$ ), technical problems (4.4\% and $8.8 \%)$ and difficult to find what I need (2.9\% and 7\%).

\section{What the website is used for}

Altogether, $72.5 \%$ of the website users reported using the site to keep up-to-date with information in their fields and almost $60 \%$ for the purpose of educating themselves. More than one-half of users (52.7\%) reported using it as a starting point to prepare lectures, one-third (33.5\%) to retrieve information for their research and $5.5 \%$ of the respondents to access the site specifically to earn CME credits.

\section{Types of content used}

Respondents to the online survey were asked to rate the importance of different types of content available on the website (Figure 4). PPT slides and journal articles ranked the highest, followed by webcasts and clinical case reports. An analysis by age groups demonstrates that younger users rate features more highly than older users, which reflects their more regular use of the website. Differences are particularly significant with regard to multimedia materials such as webcasts $(3.31$ were among the age group of below 35 years and 1.8

Medical social network

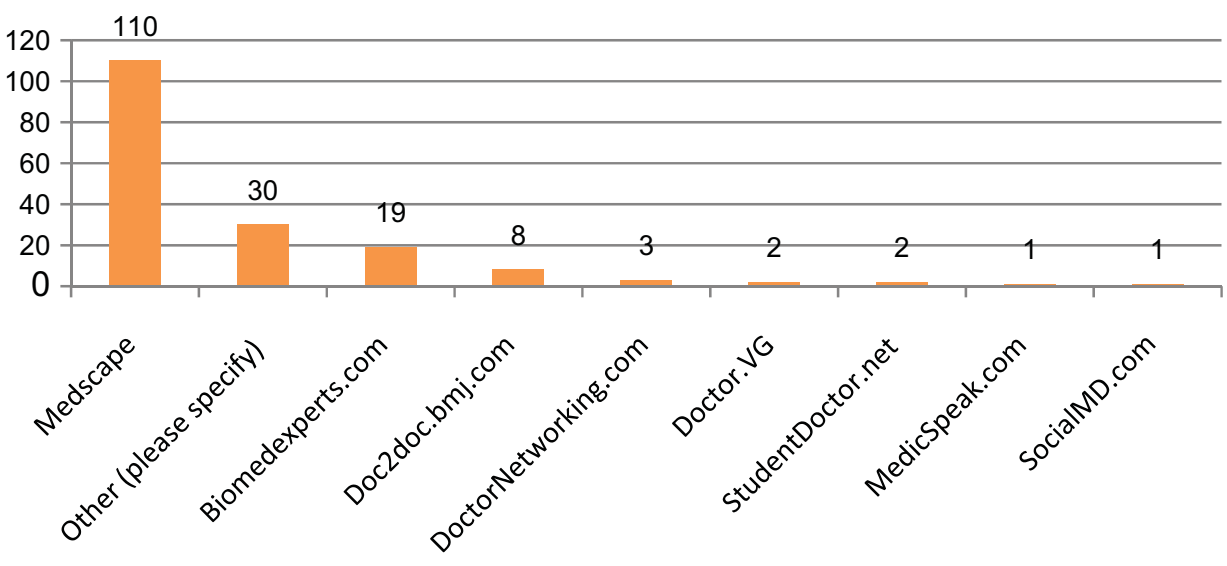

Figure 2. Use of medical social networks among respondents. 


\section{Social networks}

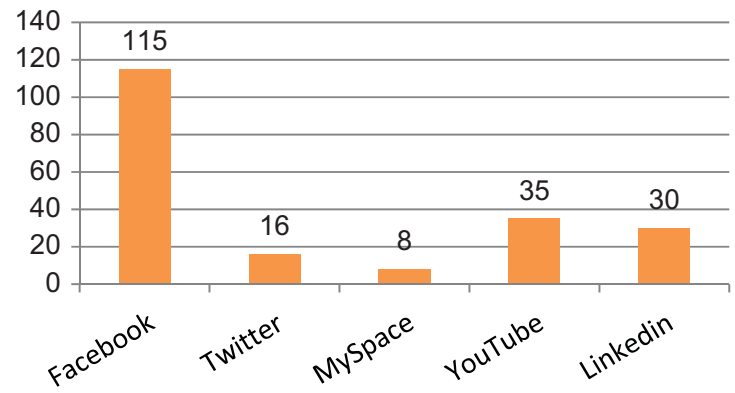

Figure 3. Use of social networks among respondents.

were above 60 years), as well as for interactive or guided educational content, such as clinical cases (3.30 vs. 1.70), educational tracks ( 3.33 vs. 1.60 ) and CME tests ( 2.98 vs. 1.60). Conversely, older respondents preferred predominantly informative materials, such as the introduction of daily news features (4.00 vs. 3.57$)$ and journal access (4.20 vs. 4.00 ).

Respondents to the telephone survey reported using journal articles and PPT slides in priority, followed by guidelines, webcasts and clinical case reports. In each of these questions, content for mobile phones or PDAs ranked low.

Respondents to the online survey were asked to rate the importance of different features available on the website. The Topics feature (Figure 5), which offers access to a thematic classification of all archived materials in the form of a mindmap, was ranked "highly important" by the most respondents.

\begin{tabular}{lcc}
\multicolumn{3}{l}{ Table 2. Frequency of website use among respondents. } \\
\hline Frequency of use & Completed online & Completed on the phone \\
\hline Daily & 14 & 4 \\
Weekly & 78 & 61 \\
Monthly & 147 & 66 \\
3-6 times a year & & 9 \\
Occasionally & & 42 \\
Never & 57 & 68 \\
\hline
\end{tabular}

This was followed by the search function and by the more traditional "Browse by event/publication". Fewer than $50 \%$ of respondents ranked the availability of online CME tests as important or highly important (Figure 6).

These preferences reflect actual usage statistics from the ERS education website, which consistently show that PDF materials as well as PPT slides are by far the most frequently downloaded types of materials; download of multi-media materials, such as podcasts being much more sporadic.

In the final section of the surveys, users were asked which potential future developments would make the ERS education website more attractive to them (Figure 7).

Respondents to the web survey ranked a range of pre-defined features. Guideline-related features ranked highest for most respondents (easy-to-print guidelines and slide kits for guidelines). Another popular feature was teaching-related material (teaching videos of medical procedures and teaching slide kits). Finally, the development of an online encyclopaedia for respiratory

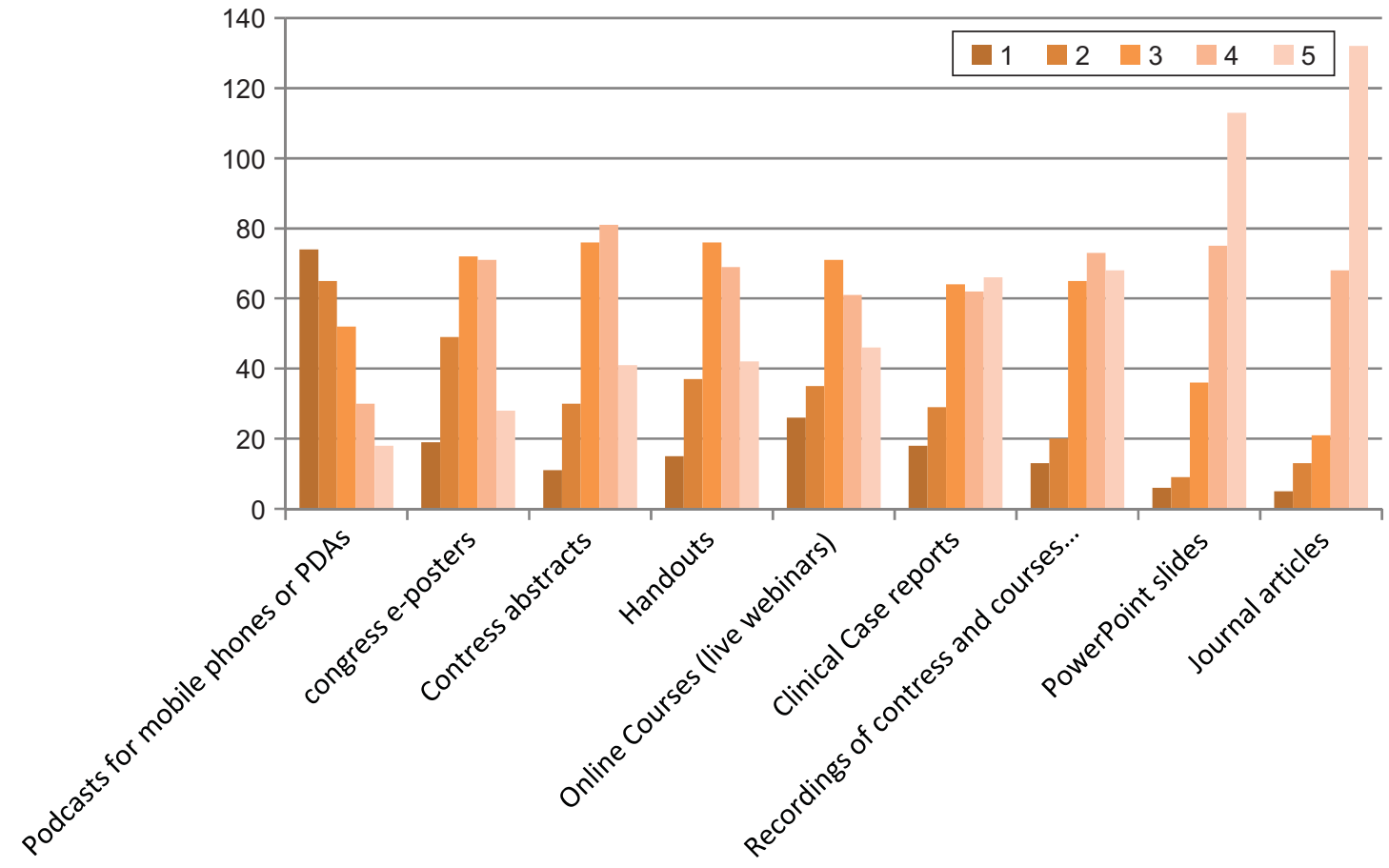

Figure 4. Importance of the types of content among respondents (5 highly important, 1 not important). 


\section{ERS \\ RESPIRATO}

HOME
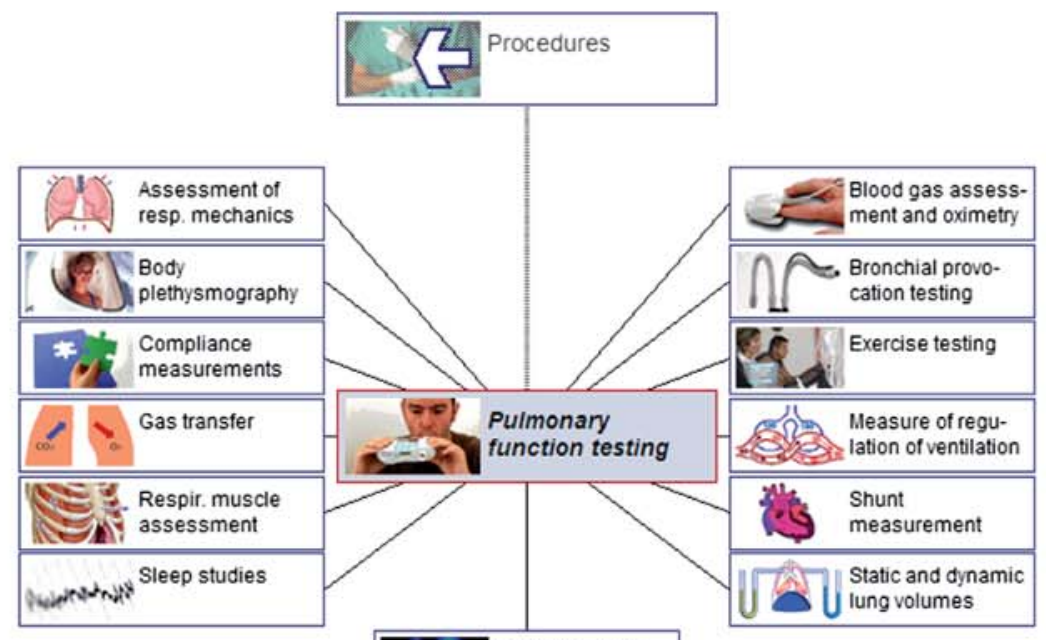

Ventilation-perfu-

sion measurement

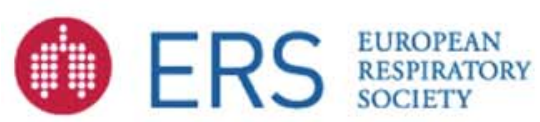

\begin{tabular}{l|l|l|l|l|l}
\hline HOME & EVENTS & GUIDELINES & PUBUCATIONS & TOPICS & MULTIM:
\end{tabular}

You are here : ERS > E-Resources > Topics > Procedures > Pulmonary function testing > Compliance measurements - interpretation

*11 Compliance measurements - interpretation

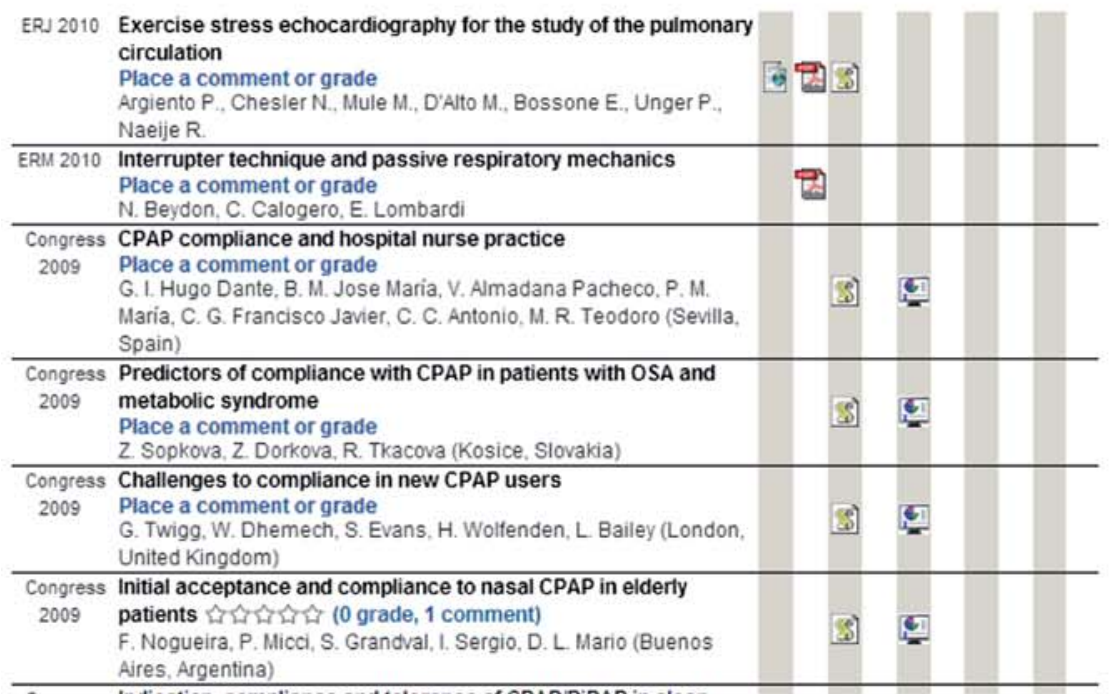

Figure 5. ERS website displaying mindmap overview of pulmonary function testing procedures. 


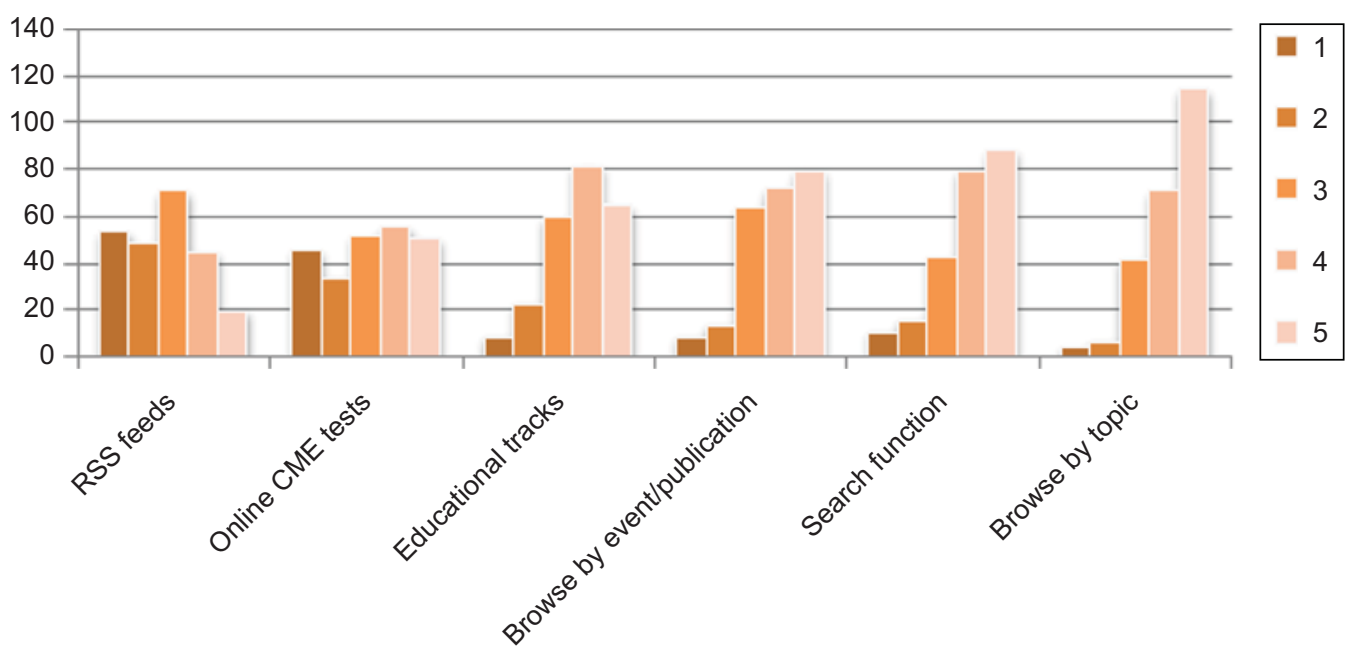

Figure 6. Importance of website features and functionalities among respondents.

medicine (similar to Wikipedia) ranked high as well. Open comments only reinforced the interest in some of these features, but did not bring any new ideas. In addition, some comments on the need for more resources linked to particular fields of interest were made (i.e. more paediatrics, more nursing, more chronic obstructive pulmonary disease resources).

Responses obtained from telephone interviewees were very similar (Table 3), with access to guidelines mentioned most frequently, followed by issues such as links to articles in other journals, highlights, more teaching materials, more clinical case studies, more interactive sessions, more online courses, forums for discussions and more recordings of courses and lectures. Nine users and three non-users mentioned that they would like to have more clinical case studies on the site. Several website users (nine) and nine non-users indicated they would need more teaching materials, in general. In addition to an overall request for materials that could be used for teaching, there were also requests for videos, animations, more PPT slides and pictures, $\mathrm{X}$-rays or photos of diseases. These were for use in teaching and learning.

\section{Discussion}

Web-based learning has multiple facets and is provided through a variety of channels and media, and although literature often refers to online-learning as a single entity, a recent systematic review demonstrated large heterogeneity in delivery channels. ${ }^{3}$ The ERS education website has been developed to provide a wide range of relevant information in different formats, using both a traditional website and an elaborated learning man-

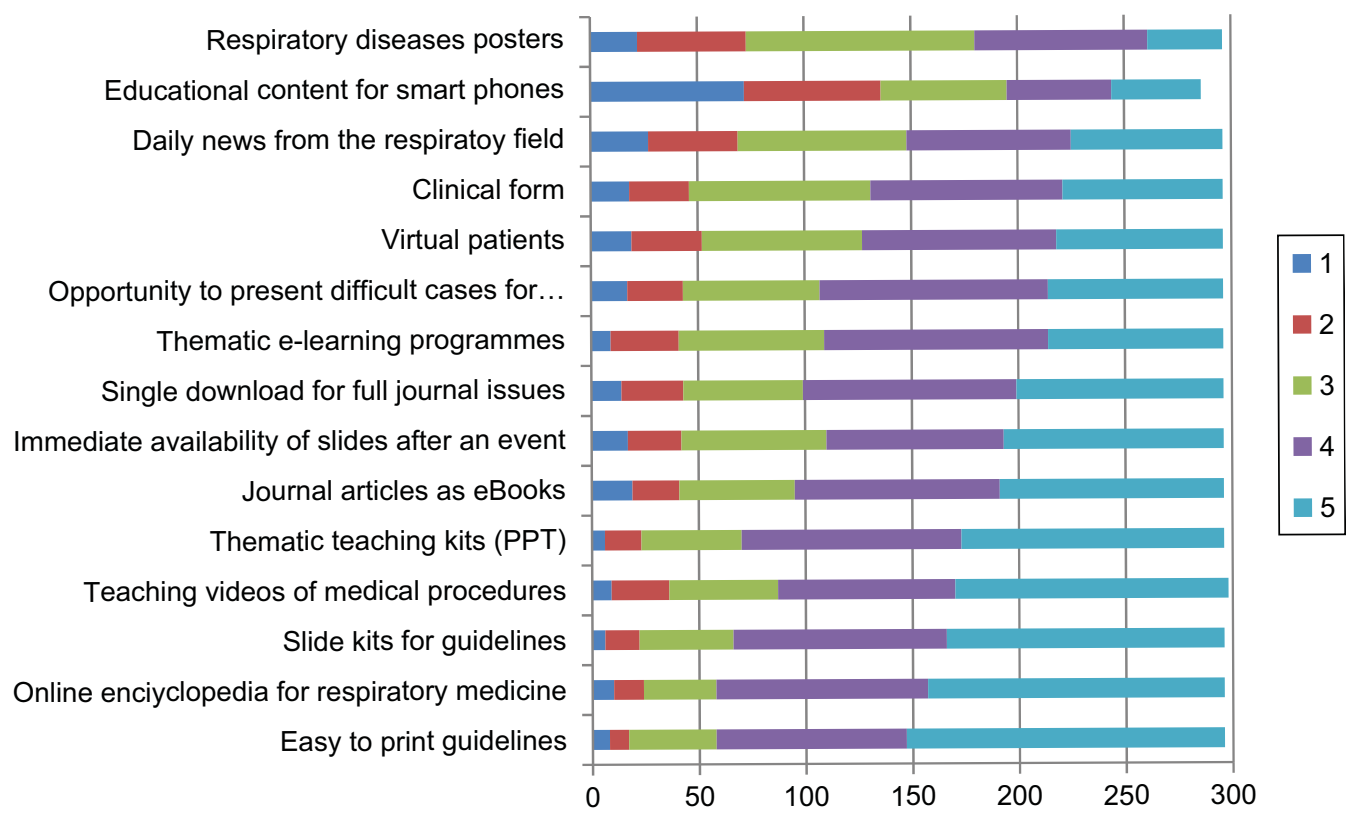

Figure 7. Requests for further developments and improvements ranked by importance by online respondents. 
Table 3. Requests for further developments and improvements quoted by telephone interviewees.

\begin{tabular}{|c|c|c|c|}
\hline Improvements needed - users & \# of mentions & Must-haves for the ideal educational site - non users & \# of mentions \\
\hline More guidelines & 24 & Links to articles on other journals & 14 \\
\hline Navigation: make it easier to reach the information & 18 & Guidelines & 13 \\
\hline Highlights of latest developments and most important reads & 15 & Basic information on respiratory diseases & 11 \\
\hline Links to articles in other journals & 13 & Teaching materials & 9 \\
\hline Requests for specific educational information & 13 & Videos and animations & 9 \\
\hline Search engine needs to be improved & 12 & PowerPoint slides to be used for teaching & 8 \\
\hline Access to the site, include a link from the main ERS webpage & 10 & Pictures of diseases & 7 \\
\hline Alerts: email alerts of new updates & 10 & Navigation: make it easy to reach the information & 5 \\
\hline More clinical case studies & 9 & Highlights of latest developments and most important reads & 5 \\
\hline Teaching materials & 9 & Alerts: email alerts of new updates & 5 \\
\hline Videos and animations & 8 & Search engine needs to be good & 4 \\
\hline Discussion forum for help, advice and networking & 7 & Interactive sessions & 4 \\
\hline Interactive sessions & 7 & Reviews of journal articles & 4 \\
\hline Basic information on respiratory diseases & 6 & Requests for specific educational information & 3 \\
\hline Recordings of courses and lectures & 6 & Plenty of clinical case studies & 3 \\
\hline Webinars should be more available & 6 & Online Courses & 3 \\
\hline SmartPhone applications & 5 & Statistics & 3 \\
\hline Quick reference guidelines & 6 & Just good, quality educational information in general & 2 \\
\hline More online courses & 5 & Patient information, brochures & 2 \\
\hline More PowerPoint slides & 5 & Clinical Case Studies & 2 \\
\hline Design: the layout is too busy & 4 & Discussion forum for help, advice and networking & 1 \\
\hline Language help & 4 & More science, more on research & 1 \\
\hline Reviews of journal articles & 4 & Communication towards members since many do not know about the site & 1 \\
\hline Pictures of diseases & 4 & Podcasts & 1 \\
\hline More science, more on research & 3 & CME opportunities & 1 \\
\hline Meetings and conferences updates & 3 & Working group involvement & 1 \\
\hline More ways to earn CME credits online & 2 & References/recommendations for educational books & 1 \\
\hline $\begin{array}{l}\text { Communication towards members since many do not know } \\
\text { about the site }\end{array}$ & 2 & & \\
\hline Just more educational information, in general & 2 & & \\
\hline Monographs & 1 & & \\
\hline Working group involvement & 1 & & \\
\hline Career advice & 1 & & \\
\hline Drug database & 1 & & \\
\hline Recordings of respiratory sounds & 1 & & \\
\hline Hermes curriculum & 1 & & \\
\hline More podcasts & 1 & & \\
\hline Training on techniques & 1 & & \\
\hline
\end{tabular}

agement system (LMS) with the purpose to educate, communicate and reach out to the professionals in the respiratory field. Materials that are used within guided learning modules leading to self-assessment quizzes and CME credits are incorporated in learning management software, which allows users' activity to be tracked. However, most materials, which are offered for consultation and self-learning purposes, are directly available through the website for download and user activity is not tracked.

The two surveys that were conducted provided an extensive amount of knowledge and visibility about the information-seeking behaviour of respiratory professionals as well as about their current needs and perceptions with regard to the way educational information is presented to them.

First, it needs to be stressed that the results of both surveys are highly similar. This is in line with previous marketing-related studies that showed a high level of correlation between traditional telephone surveys and web surveys, at a much lower cost. ${ }^{4-6}$ The only striking difference is the high level of participation from respondents from eastern Europe in the web survey, which might indicate that online access is very important for those who have less financial resource to travel and thus less direct access to world-renowned experts.

In terms of purpose, most respondents reported using the education website to keep their knowledge up-to-date and for general educational purposes. This is fully in line with previous studies on physicians' Internet information-seeking behaviour, which ranked information related to a specific patient problem, accessing latest research on specific topics and new information in a given disease area as the main reasons for looking up information on the web. ${ }^{7,8}$ In addition, more than $50 \%$ of the respondents reported using the site to help them prepare lectures. This indicates a good balance between self-directed learning and teaching needs. This also reflects the fact that current ERS membership consists mostly of rather "senior" physicians rather than young trainees. 
With regard to the content offered, the most popular features were journal articles and PPT slides, and the most frequently requested features were guidelinerelated materials (more guidelines, slide kits, easyto-print guidelines), teaching PPT kits and teaching videos. Conversely, some currently available features did not rank very highly, either in quality or in importance, particularly RSS feeds and mobile phone/PDA contents. These preferences, which truthfully reflect actual download statistics from the website, are a clear indication that even if today's technology allows the creation of many different formats and features, we must keep in mind that established forms of accessing information and learning are still crucial to both learners and teachers. However, differences between age-groups, which are not apparent in anonymised download statistics, indicate a gradual trend towards multimedia materials, which are highly appreciated by younger users.

With regard to CME credits, even though tests are readily accessible and regularly taken, this is seldom listed as an ultimate objective in using the website, which seems to indicate a desire and need to access information rather than a need to validate what has been read/ learnt. Again, this is in line with previous studies, which revealed that $70 \%$ of users reported rarely or never accessing on-line CME. ${ }^{8}$ That said, although currently the need to collect CME credits online seems rather modest, a 2010 published study demonstrates an exponential growth in the number of online CME credits available, and forecasts that even though online CME was $6.9-8.8 \%$ of CME undertaken in 2008, it is likely to increase to $50 \%$ of all CME undertaken within $7-10$ years. ${ }^{9}$ A similar study performed in 3-5 years' time might therefore reveal a very different picture.

\section{Conclusion}

Although this study was restricted to respiratory physicians, other medical specialties or subspecialties might very well observe similar trends, and our concluding considerations might apply to areas other than respiratory medicine.

This survey demonstrates a very widespread use of the Internet for seeking professional information and continuing learning among respiratory professionals. It also demonstrates that although a wide variety of different educational formats is readily available, respiratory professionals have a strong inclination towards well-established learning materials. Therefore, although technology allows a wide variety of formats and features for providing multimedia content, traditional formats, such as PDFs and PPTs should not be disregarded as they are still widely consulted and used. Further, reported use made of the materials accessed by physicians demonstrates that educational websites should take into account the needs of both learners and teachers, as the materials available are equally used for self-directed learning and in the preparation of lectures. With regard to CME testing, the availability of validated CME tests at the end of a CME activity is appreciated, but currently it is seldom considered as a necessity by most physicians.

Finally, even though senior physicians have a strong preference for traditional learning/teaching formats, use of social networks such as Facebook and of advanced technology, such as smartphones, is much more prevalent among younger doctors, thus indicating that needs and preferences might significantly change in the next $5-10$ years.

\section{Declaration of interest}

\section{Funding}

No commercial support was provided for this manuscript.

\section{Author(s) Financial Disclosure}

T.S. has disclosed that she has no relevant financial relationships.

P.K. has disclosed that he has no relevant financial relationships.

P.P. has disclosed that he has no relevant financial relationships.

A.S. has disclosed that she has no relevant financial

J.V. has disclosed that he has no relevant financial Relationships

\section{Peer Reviewers Financial Disclosure}

Peer Reviewer 1 has disclosed that he has no relevant financial relationships.

Peer Reviewer 2 has disclosed that he has no relevant financial relationships.

\section{References}

1. Masters K. For what purpose and reasons do doctors use the Internet: A systematic review. Int J Med Inform 2008;77:4-16.

2. Hall \& Partners and Google Custom HCP Study, August 2009. http://www.fdasm.com/docs/Connecting\%20with\%20Physi cians\%20Online\%20Webinar\%20Deck--\%20FINAL.PDF.

3. Cook DA, Garside S, Levinson AJ, et al. What do we mean by webbased learning? A systematic review of the variability of interventions. Med Educ 2010;44:765-774.

4. Braunsberger K, Wybenga H, Gates R. A comparison of reliability between telephone and web-based surveys. J Bus Res 2007; 60: $758-764$.

5. Klein D, Roster CA, Rogers RD, et al. A comparison of response characteristics from web and telephone surveys. Int J Market Res 2004;46:359-373.

6. Carini RM, Hayek JC, Kuh GD, et al. College student responses to web and paper surveys: Does mode matter? Res High Educ 2003; 44:1-19.

7. Bennett NL,Casebeer LL, Kristofco RE, et al. Physicians' internet information-seeking behaviors. J Contin Educ Health Prof 2004;24: $31-38$.

8. Casebeer L, Bennett N, Kristofco R, et al. Physician internet medical information seeking and on-line continuing education use patterns. J Contin Educ Health Prof 2002;22:33-42.

9. Harris JM, Sklar, Amend RW, et al. The growth, characteristics and future of online CME. J Contin Educ Health Prof 2010;30:3-10. 